\title{
Aripiprazole monotherapy in the treatment of bipolar disorder: a meta-analysis
}

\author{
Konstantinos N Fountoulakis ${ }^{1 *}$, Eduard Vieta ${ }^{2}$, Frank Schmidt ${ }^{3}$ \\ From $1^{\text {st }}$ International Congress on Neurobiology and Clinical Psychopharmacology and European \\ Psychiatric Association Conference on Treatment Guidance \\ Thessaloniki, Greece. 19-22 November 2009
}

\section{Background}

The current article is a systematic registration and meta-analysis of the available clinical trials concerning the usefulness of aripiprazole in the treatment of bipolar disorder.

\section{Materials and methods}

A systematic MEDLINE and repositories search concerning treatment guidelines and clinical trials for aripiprazole in bipolar disorder.

\section{Results}

The pooled effect size for acute mania was equal to 0.34 . The NNT was 6 for aripiprazole vs placebo concerning response at week 3 and equal to 14 concerning remission. The average day response started was day 3 . The switch rates were peculiarly in favour of haloperidol and against lithium. The suicide rates were negligible for all groups. The meta-analysis for acute bipolar depression suggests a significant difference at week 8 with an effect size 0.17 . The maintenance data suggest that the median survival time for the aripiprazole group was not evaluable, while the median survival time for placebo was 118-203 days depending on the clinical subpopulation.

\section{Conclusions}

The data analysed for the current study support the usefulness of aripiprazole during all phases of bipolar illness, inpite of the rather weak effect on depression and that the efficacy during the maintenance period is proven only against new manic episodes and in patients with an index manic episode who responded to aripiprazole during the acute phase.

\footnotetext{
13rd Department of Psychiatry, Aristotle University of Thessaloniki, Greece
}

\section{Author details}

'3rd Department of Psychiatry, Aristotle University of Thessaloniki, Greece. ${ }^{2}$ Bipolar Disorders Program, Hospital Clinic, University of Barcelona, IDIBAPS, CIBERSAM, Barcelona, Spain. ${ }^{3}$ Fethke Professor, Tippie College of Business, University of lowa, USA.

Published: 22 April 2010

doi:10.1186/1744-859X-9-S1-S224

Cite this article as: Fountoulakis et al.: Aripiprazole monotherapy in the treatment of bipolar disorder: a meta-analysis. Annals of General Psychiatry 2010 9(Suppl 1):S224.
Submit your next manuscript to BioMed Central and take full advantage of:

- Convenient online submission

- Thorough peer review

- No space constraints or color figure charges

- Immediate publication on acceptance

- Inclusion in PubMed, CAS, Scopus and Google Scholar

- Research which is freely available for redistribution
C Biomed Central 